\title{
Volatility in asset prices and long-run wealth effect estimates
}

\author{
Fernando Alexandre ${ }^{\mathrm{a}, \mathrm{b}}$, Pedro Bação ${ }^{\mathrm{c}, \mathrm{d}}$, Vasco J. Gabriel ${ }^{\mathrm{e}, \mathrm{b}, *}$ \\ a Departamento de Economia, Escola de Economia e Gestão, Universidade do Minho, \\ Campus de Gualtar, 4710-057 Braga, Portugal \\ ${ }^{\mathrm{b}}$ Núcleo de Investigação em Política Económica, Universidade do Minho, Portugal \\ ${ }^{\mathrm{c}}$ Faculdade de Economia da Universidade de Coimbra, Av. Dias da Silva 165, 3004-512 Coimbra, Portugal \\ ${ }^{\mathrm{d}}$ Grupo de Estudos Monetários e Financeiros, Universidade de Coimbra, Portugal \\ e Department of Economics, University of Surrey, Guildford, Surrey, GU2 7XH, UK
}

Accepted 24 April 2007

\begin{abstract}
We argue that the equation commonly used in the estimation of the wealth effect on consumption might be unsuitable for that purpose. In particular, if the usual assumptions are employed, the derivation of the equation implies that the wealth effect is indeterminate. Furthermore, it implies that the estimate of the wealth effect should decrease when asset wealth volatility increases. Estimation of a Markov-switching model of the usual long-run aggregate consumption equation provides evidence favourable to the indeterminacy hypothesis. (C) 2007 Elsevier B.V. All rights reserved.
\end{abstract}

JEL classification: C51; C52; E21; E44; G10

Keywords: Parameter instability; Markov switching; Consumption; Wealth effect

\section{Introduction}

The 1990s witnessed a remarkable increase in stock prices in the USA. Between January 1995 and September 2000, the S\&P 500 stock price index rose approximately by $230 \%$. According to Poterba (2000) this increase accounted for more than $60 \%$ of the wealth creation in the USA

\footnotetext{
* Corresponding author. Department of Economics, University of Surrey, Guildford, Surrey, GU2 7XH, UK. Tel.: +44 1483 682769; fax: +44 1483689548 .

E-mail addresses: falex@eeg.uminho.pt (F. Alexandre), pmab@fe.uc.pt (P. Bação), v.gabriel@surrey.ac.uk (V.J. Gabriel).
} 
during that period. Boom/bust periods in stock markets, and their effects on total wealth and consumption, have raised several questions for economic analysis. In particular, there is an ongoing debate on the appropriate monetary policy response to movements in stock prices. One of the topics of the debate concerns the effect of rising asset prices on inflation. Rises in asset prices are accompanied by rises in consumer wealth, which may lead to an increase in consumption. This increase in consumption could put pressure on consumer prices, and this pressure may warrant a restrictive monetary policy move. To determine the practical relevance of this channel - the wealth effect - it is necessary to build and estimate appropriate econometric models.

An important example of this line of research is Ludvigson and Steindel (1999). These authors estimate the wealth effect to be the usual 0.04 for their full sample, 1953-1997. However, their estimate reaches 0.1 in the 1976-1985 sub-sample, and is only 0.02 after 1986 . Results such as these have led several authors to question and further investigate the stability of estimates of the wealth effect. The results reported in Mehra (2001) show that the estimate seems to depend on the econometric model, the measures of wealth and consumption, and on the sample. Poterba (2000) puts forward several reasons that might explain the observed signs of instability. In this paper we report additional empirical evidence on, and provide an alternative explanation of, the instability of the estimated wealth effect.

The approach we take here starts where Lettau and Ludvigson (2001) stopped. Lettau and Ludvigson (2001, p. 823) note that their estimates of the long-run aggregate consumption function are consistent with what one would expect if aggregate production is governed by a Cobb-Douglas technology. The purpose of this paper is to show that, if this is indeed the case, then either the usual long-run aggregate consumption function does not represent a cointegrating relation, or the "wealth effect" is indeterminate. Rudd and Whelan (2006) have taken the first route, i.e., they argue that there is no cointegration between consumption, wealth and labour income, for which they employ a different dataset from that used by Lettau and Ludvigson. Here we pursue the second possibility, working on the same dataset as Lettau and Ludvigson (2004).

Our empirical evidence is based on a Markov-switching (MS) model of consumption and appears to corroborate our analysis of the standard model. The estimated MS model, which offers a convenient way to test for and characterise the instability of the estimated wealth effect, separates the data into two regimes; importantly, the regime with the lower estimated "wealth effect" occurs in periods of higher asset-price volatility. If financial markets do behave in a regime-switching way (or at least, financial volatility varies with time), then our results show the impact of such regime switching on estimates of the "wealth effect", corroborating our hypothesis concerning the indeterminacy of the "wealth effect".

The paper is structured as follows. In the next section, we show that standard theoretical assumptions about consumption and output functions may lead to difficulties in the estimation and interpretation of the wealth effect. In Section 3, we estimate a cointegrated Markov-switching model that will allow us to examine sub-samples (endogenously selected) associated with different estimates of the wealth effect. We relate these sub-samples to periods characterised by different levels of volatility in asset wealth. Section 4 concludes.

\section{The wealth effect}

In this section, we start by presenting the standard equation used to estimate the wealth effect on consumption. Then, following Lettau and Ludvigson (2001) remark that their estimates of the long-run aggregate consumption function are consistent with a Cobb-Douglas production 
function and using simple macroeconomic identities and results, we deduce steady-state relations which represent attractors for the long-run trends in the variables. We shall then revert to observed values by adding to the long-run trends the short-run deviations. Finally, we will discuss the meaning of estimates of the wealth effect.

\subsection{The standard model}

The standard derivation of the equation employed to estimate the wealth effect on consumption - see, e.g., Lettau and Ludvigson (2001) - begins by assuming that consumption tends to a stationary fraction of total wealth, which allows us to write a cointegrating relation between (the $\operatorname{logs}$ of) consumption $\left(c_{\mathrm{t}}\right)$ and total wealth $\left(w_{\mathrm{t}}\right)$ :

$$
c_{\mathrm{t}}-w_{\mathrm{t}}=u_{\mathrm{t}},
$$

where $u_{\mathrm{t}}$ is a stationary process and equals the log consumption-wealth ratio. Such a result may be obtained from the usual micro-founded model of consumption - e.g., Campbell and Mankiw (1989) - if one assumes that the period utility is well approximated by a log function of consumption. The derivation then proceeds to separate total wealth into human and non-human wealth:

$$
w_{\mathrm{t}} \approx \omega a_{\mathrm{t}}+(1-\omega) h_{\mathrm{t}},
$$

where $a_{\mathrm{t}}$ is $\log$ non-human wealth, $h_{\mathrm{t}}$ is $\log$ human wealth and $\omega$ is the average weight of nonhuman wealth in total wealth. Human wealth is not observable, but Lettau and Ludvigson (2004) argue that an approximation ${ }^{1}$ may be obtained by using labour income, $y_{\mathrm{t}}$, as a proxy for $h_{\mathrm{t}}$, resulting in the following log consumption-wealth ratio:

$$
c_{t}-\omega a_{t}-(1-\omega) y_{t}=u_{t}^{*} .
$$

These authors show that, on a set of US data, $c_{t}, a_{t}$ and $y_{t}$ share a common trend, with normalised cointegration vector $(1,-\beta,-\delta)$ and cointegration residual $c_{t}-\beta a_{t}-\delta y_{t}$ (cay in brief). The coefficient $\beta$ is interpreted as the "wealth effect". Lettau and Ludvigson (2001) report estimates of $\hat{\beta}=0.3$ and $\hat{\delta}=0.6$.

Lettau and Ludvigson (2001) note that the estimated coefficients (0.3 and 0.6) are what one would expect if the aggregate production were well represented by a Cobb-Douglas, since they are very close to the usual income shares of capital and labour. Next, we follow Lettau and Ludvigson's lead and explicitly use a Cobb-Douglas production function as the starting point to our analysis.

\subsection{Interpreting long-run wealth effect estimates}

In order to derive steady-state relations for the consumption-wealth ratio, we begin by noting that, using national accounting identities, consumption can be written as $C=O-X$, where $O$ stands for output and $X$ stands for uses of output other than consumption. Thus, one first needs to describe the dynamics of output, and then establish assumptions regarding the role of $X$.

\footnotetext{
${ }^{1}$ See Lettau and Ludvigson (2001) or Lettau and Ludvigson (2004) for a more detailed discussion of the assumptions employed in the approximation.
} 
If we follow Lettau and Ludvigson's suggestion, then aggregate output is given by the following Cobb-Douglas function:

$$
O_{\mathrm{t}}=K_{\mathrm{t}}^{\alpha} L_{\mathrm{t}}^{1-\alpha},
$$

where $K$ and $L$ denote capital and labour, respectively. Therefore, labour income is $Y_{\mathrm{t}}=(1-\alpha) O_{\mathrm{t}}$ and the return to capital (total "dividends") is $R_{\mathrm{t}}=\alpha O_{\mathrm{t}}$, where the capital share, $\alpha$, is assumed to be constant - see, e.g., Hornsein et al. (2005) for an analysis of the labour/capital share in the US economy.

As Lettau and Ludvigson pointed out, there is a clear link between asset markets and consumption, so one must characterise the behaviour of the return to capital $R_{\mathrm{t}}$. For that purpose, first note that we can also write as $R_{\mathrm{t}}=D_{t} K_{t}$, i.e., dividends per unit of capital, $D_{\mathrm{t}}$, times the capital stock, $K_{\mathrm{t}}$. Secondly, we can resort to a standard macroeconomic asset-pricing model — see, e.g., Ljungqvist and Sargent (2004), which says that the current price of an asset (in this case, capital) is the expected discount sum of future dividends:

$$
Q_{t}=E_{t}\left[m_{t+1}\left(Q_{t+1}+D_{t+1}\right)\right]
$$

where $Q_{t}$ is the asset price and $m_{t}$ is the stochastic discount factor. In steady state, the relation between asset prices and dividends is given by the following equation:

$$
Q=\frac{m}{1-m} D \text {. }
$$

Furthermore, notice that asset wealth is $A=(Q+D) K$, that is, cum-dividend price times asset volume, and that the product of $D \times K$ is just the steady-state return to capital. Then, using the steady-state return to capital from the Cobb-Douglas function $(R=\alpha O)$, we have:

$$
A=(Q+D) K=\frac{D}{1-m} K=\frac{\alpha}{1-m} O .
$$

With steady-state labour income given by $Y=(1-\alpha) O$, for an arbitrary $\theta$,we can now write consumption as:

$$
C=O-X=\theta \frac{1-m}{\alpha} A+(1-\theta) \frac{1}{1-\alpha} Y-X .
$$

According to this equation, in the long run, consumption is not related to labour income and non-human wealth alone, but also to other components of aggregate output. Since consumption models, as the one described above, do not include these other elements, we need an assumption to justify the existence of a cointegrating relation between consumption, asset wealth and income. For simplicity, we assume $X=0 .^{2}$

With this assumption,

$$
C=\theta \frac{1-m}{\alpha} A+(1-\theta) \frac{1}{1-\alpha} Y,
$$

\footnotetext{
${ }^{2}$ It is important to stress that this assumption leads to the same conclusions as assuming that $X$ is stationary, or that $X$ is cointegrated with asset wealth and labour income, or still that consumption is a constant fraction of output, i.e., the average propensity to consume is constant in the long run, which is a stylised fact of macroeconomics and an implication of Galí (1990) microfounded model of consumption.
} 
i.e., if we run the usual regression in levels, the "wealth effect" is indeterminate, since $\theta$ is arbitrary. Nevertheless, it is common to run the regression in logs. In this case the usual first order Taylor approximation gives (ignoring a constant):

$$
c=\rho_{a} a+\rho_{y} y,
$$

where the coefficients are:

$$
\begin{aligned}
& \rho_{a}=\frac{\theta(1-m) \alpha^{-1} A}{C}=\theta \frac{O}{C}=\theta, \\
& \rho_{y}=\frac{(1-\theta)(1-\alpha)^{-1} Y}{C}=(1-\theta) \frac{O}{C}=1-\theta .
\end{aligned}
$$

Again we find that the aggregate long-run wealth effect is indeterminate. If this were really the case, one would expect the estimated coefficients to depend on short-run correlations between the variables. This would result in instability of the coefficients as one varied the sample. To see this, note that the previous equations relate steady-state values, which we interpret as long-run trends. Let the observed values be:

$$
\begin{aligned}
& \tilde{c}_{t}=c+\varepsilon_{t}^{c}, \\
& \tilde{a}_{t}=a-\varepsilon_{t}^{a}, \\
& \tilde{y}_{t}=y-\varepsilon_{t}^{y,}
\end{aligned}
$$

where the added disturbances reflect short-run deviations from the long-run trend. Then, in terms of observed values, we have:

$$
\tilde{c}_{t}=\rho_{a} \tilde{a}_{t}+\rho_{y} \tilde{y}_{t}+\rho_{a} \varepsilon_{t}^{a}+\rho_{y} \varepsilon_{t}^{y}+\varepsilon_{t}^{c} .
$$

Minimisation of the variance of the residual, $V\left[\rho_{a} \varepsilon_{t}^{a}+\rho_{y} \varepsilon_{t}^{y}+\varepsilon_{t}^{c}\right]$, with respect to $\theta$ leads to the following estimate of the wealth effect:

$$
\rho_{a}=\theta=\frac{\sigma_{y y}-\sigma_{y a}+\sigma_{y c}-\sigma_{a c}}{\sigma_{y y}+\sigma_{a a}-2 \sigma_{y a}},
$$

where $\sigma_{i j}=E\left(\varepsilon_{t}^{i} \varepsilon_{t}^{j}\right)$, with $i, j=c, a, y$, represent variances and covariances in the short run.

This result and the reasoning leading to it suggest that there may be reasons for concern regarding the relevance of empirical estimates of the wealth effect in the context of a standard macro model. The estimates may reflect short-term correlations, possibly mixed with long-run parameters, as in the regression in levels - recall Eq. (9).

Although most of the terms in Eq. (17) seem to have been reasonably stable over time, that is not the case with asset wealth. In fact, changes in asset wealth are almost indistinguishable from movements in stock market returns. Fig. 1 depicts the log difference of quarterly asset wealth and stock returns from the Standard \& Poor's Composite Index, making the similarities quite visible (the correlation is close to 0.9). Several papers document the existence of different regimes in financial markets, linked with asset price volatility - see Cecchetti et al. (1990), Driffill and Sola (1998) and Guidolin and Timmerman (2005), for example. Therefore, we should expect assetwealth volatility to display a similar time-varying behaviour. This fact is acknowledged by Lettau 


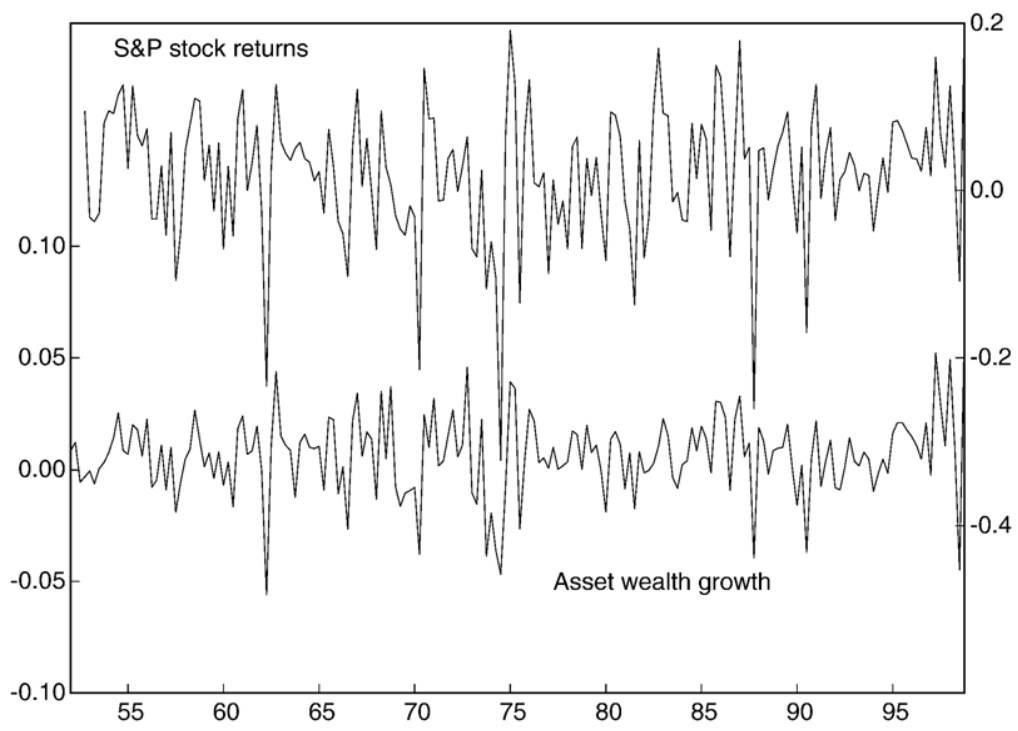

Fig. 1. S\&P stock returns and asset wealth growth.

and Ludvigson (2004, p. 277), but it is not explicitly accounted for. Indeed, in the next section, we show that such time-varying volatility patterns are a feature of the data employed by Lettau and Ludvigson (2004).

An important implication of our derivations, namely Eq. (17), is that, ceteris paribus, an increase in the variance of asset wealth should be accompanied by a reduction of the size of the estimated "wealth effect" - this is exactly what the data, as reported in the next section, shows.

\section{Empirical analysis}

The previous section discussed possible sources of instability in the "wealth effect". In this section, we reassess the empirical results of Lettau and Ludvigson (2004) and suggest an empirical framework to model instability in the consumption-wealth ratio. In what follows, and for comparability, we employ the same dataset as Lettau and Ludvigson (2004), comprising quarterly data on aggregate consumption, asset wealth and labour income, spanning from 1951:4 to 2003:3. We then check the robustness of our claims by using our approach with UK data.

\subsection{USA data}

Table 1 revisits the results in Lettau and Ludvigson (2004). Firstly, we confirm that there is indeed cointegration among consumption, labour income and asset wealth, judging by the results of Johansen cointegration tests in the top panel of Table 1. Secondly, however, it is possible that this relationship, although retaining its long-run features, may have been subject to regime shifts. Gregory and Hansen (1996) derived suitable tests for this possibility, which clearly point to the presence of cointegration with breaks: all statistics in Table 1 comfortably reject the null of no cointegration against the alternative of cointegration with shifts in the cointegration vector $(1,-\beta,-\delta)$ (corresponding to model 4 of Gregory and Hansen, 1996, p.103). We further test the stability of the cointegration vector by using Hansen (1992) single- 
Table 1

Cointegration tests

Johansen cointegration tests

\begin{tabular}{llllllr}
\hline $\mathrm{H}_{0}: r=$ & Trace & $p$-value & $5 \%$ c.v. & Max. & $p$-value & $5 \%$ c.v. \\
\hline 0 & 52.861 & 0.00 & 35.192 & 35.526 & 0.00 & 22.299 \\
1 & 17.335 & 0.121 & 20.262 & 13.726 & 0.106 & 15.892 \\
2 & 3.609 & 0.473 & 9.165 & 3.609 & 0.473 & 9.165
\end{tabular}

Gregory-Hansen cointegration tests

\begin{tabular}{lll}
$\mathrm{ADF}^{*}$ & $Z^{*}$ & $Z_{\alpha}^{*}$ \\
\hline$-6.01^{* *}$ & $-5.96^{*}$ & $-60.31^{*}$
\end{tabular}

Stability tests

\begin{tabular}{lllll}
\hline Hansen (single-equation) & Mean LM & Sup LM & Exp LM & $L_{\mathrm{c}}$ \\
\hline$p$-values & 0.045 & $>0.20$ & $3.465^{*}$ & 0.106 \\
Seo (system) statistics & $5.413^{*}$ & 9.463 & $3.255^{*}$ & \\
\hline
\end{tabular}

**:rejection at the $1 \%$ significance level; *: rejection at the $5 \%$ significance level.

equation statistics - also employed by Lettau and Ludvigson (2004) - as well as their system counterparts suggested by Seo (1998). The results are presented in the bottom half of Table 1: most tests indicate potential instability of the cointegration vector. The evidence is, in our opinion, sufficiently compelling to warrant further attention.

A possible explanation for the apparent instability is the role played by asset wealth volatility, as discussed in the previous section. Therefore, we turn our attention to the analysis of this feature. It is clear from Figs. 2 and 3, which represent the levels and growth rates of the variables, that asset wealth displays not only a much more volatile path than consumption, but also that volatility seems to be changing over time (the same applies if we linearly detrend asset wealth and look at the deviations of wealth from its long-run trend). Indeed, two simple statistical checks

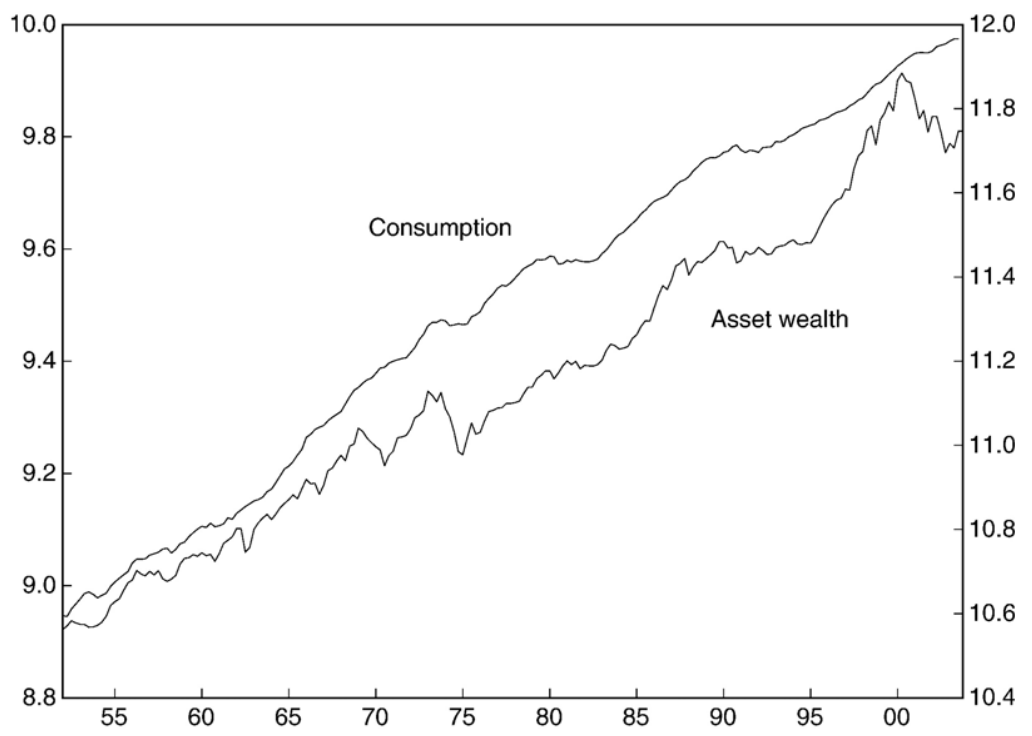

Fig. 2. Levels of consumption and asset wealth, USA. 


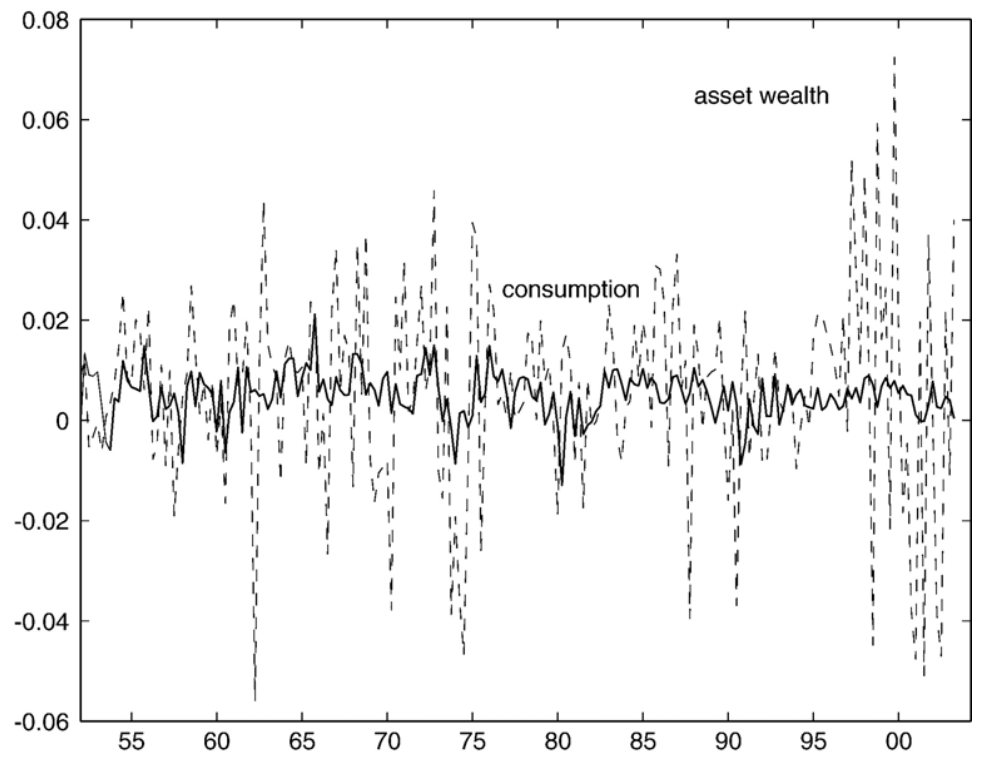

Fig. 3. Consumption and asset wealth growth, USA.

allow us to confirm this assertion. We estimated a GARCH model and a simple mean-variance switching representation for the first difference of log asset wealth, reported in Table $2 .{ }^{3}$ The results show that univariate representations with time-varying heteroskedasticity are more sensible than constant-variance ones. Fig. 4 plots the estimated variance from these two approaches, quite clearly revealing the time-varying nature of asset wealth growth volatility and showing coincident periods of high volatility. The models seem to be picking periods that one can associate with turbulent financial markets as, for example, the recent "bull" market of the late 1990s and subsequent decline.

Furthermore, we note that, in terms of the long-run consumption-wealth ratio Eq. (3), the equilibrium errors will inevitably reflect low frequency movements in volatility that are left unaccounted for. This can be seen in Fig. 5, which plots the estimated variance switches in asset wealth against $c a y_{t}$, the equilibrium errors as estimated by Lettau and Ludvigson (2004). It is clear that high volatility in asset markets matches boom periods where asset wealth surges above consumption (corresponding to negative equilibrium errors).

Having shown that asset wealth displays time-varying variance, we now focus on modelling the potential impact of this feature on estimates of the wealth effect. A suitable framework for this analysis is to allow the long-run relationship to undergo occasional discrete shifts of the Markovswitching type, as suggested by Hall et al. (1997). Also, as Fig. 5 suggests, the variance of Eq. (3) will reflect movements in asset wealth volatility, so a Markov-switching specification will be able to capture different volatility regimes.

We initially allow variance shifts and changes in cay to follow two independent Markov chains - as in McConnell and Perez-Quiros (2000), for example - and then assess whether a more parsimonious representation is valid, where regime switching is driven by the same, single

${ }^{3}$ The log-likelihood of the simple linear model is 514.99, with $\mathrm{AIC}=-4.981$ and $\mathrm{BIC}=-4.948$. 
Table 2

Time-varying variance models for asset wealth growth

Markov-switching model

\begin{tabular}{lllllll}
\hline Mean & \multicolumn{7}{c}{ Variance } \\
\cline { 1 - 2 } \cline { 5 - 7 }$\gamma_{0}$ & $\gamma_{1}$ & & $\xi_{0}$ & $\xi_{1}$ & $p$ & $q$ \\
\hline 0.0038 & 0.007 & & 0.0286 & 0.0107 & 0.9202 & 0.9466 \\
$(0.0035)$ & $(0.0012)$ & $(0.0001)$ & $(0.0001)$ & $(0.0423)$ & $(0.0252)$ \\
$p$-value LR specification test: 0.00 & Log-likelihood: 540.97 & AIC: -5.194 & & BIC: -5.097
\end{tabular}

GARCH model

Mean equation $0.0054(0.0012)$

Variance equation

$\mathrm{ARCH}(1)$

$0.1535(0.0753)$

GARCH(1)

$0.7807(0.109)$

$p$-value LR specification test: 0.00

Log-likelihood: 537.43

AI $C:-5.154$

BI $C:-5.089$

Asymptotic standard errors in parenthesis.

two-state Markov chain. This constitutes a strong robustness check on our claim that changes in the long-run parameters $\beta$ and $\delta$ are mainly driven by underlying variations in asset volatility.

Thus, we specify the cointegration equation as:

$$
c_{t}=\mu_{S_{t}}+\beta_{S_{t}} a_{t}+\delta_{S_{t}} y_{t}+\sigma_{V_{t}} \varepsilon_{t},
$$

where $\left\{\varepsilon_{t}\right\}$ is a stationary random sequence with mean zero and unit variance, while $S_{t}$ and $V_{t}$ are discrete-valued independent latent processes, uncorrelated with $\varepsilon_{t-i}$ for all $i$. These variables indicate the unobserved regimes operative at time $t$ for $\mathrm{cay}_{t}$ and the variance $\sigma_{t}$, forming a homogeneous first-order Markov chain with state space $\{0,1\}$ and transition probabilities $p=\operatorname{Pr}\left(S_{t}=1 \mid S_{t-1}=1\right)$, $q=\operatorname{Pr}\left(S_{t}=0 \mid S_{t-1}=0\right)$ and $p^{\prime}=\operatorname{Pr}\left(V_{t}=1 \mid V_{t-1}=1\right), q^{\prime}=\operatorname{Pr}\left(V_{t}=0 \mid V_{t-1}=0\right)$, respectively. Accordingly, the

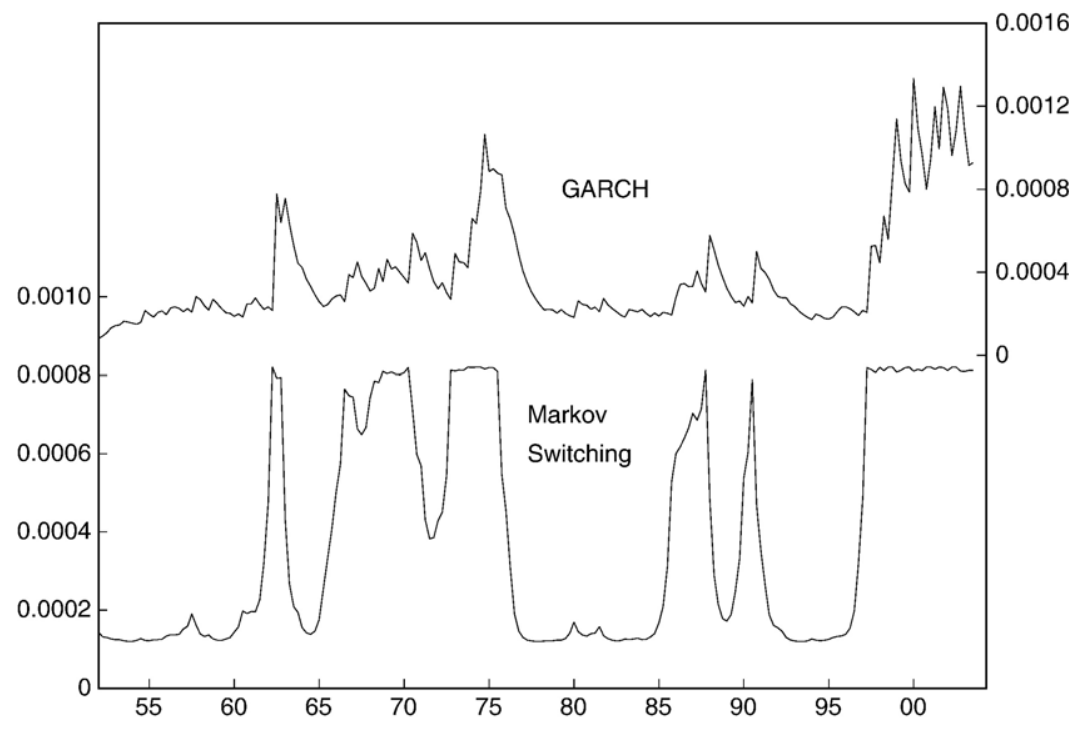

Fig. 4. Estimated time-varying variance for asset wealth growth. 


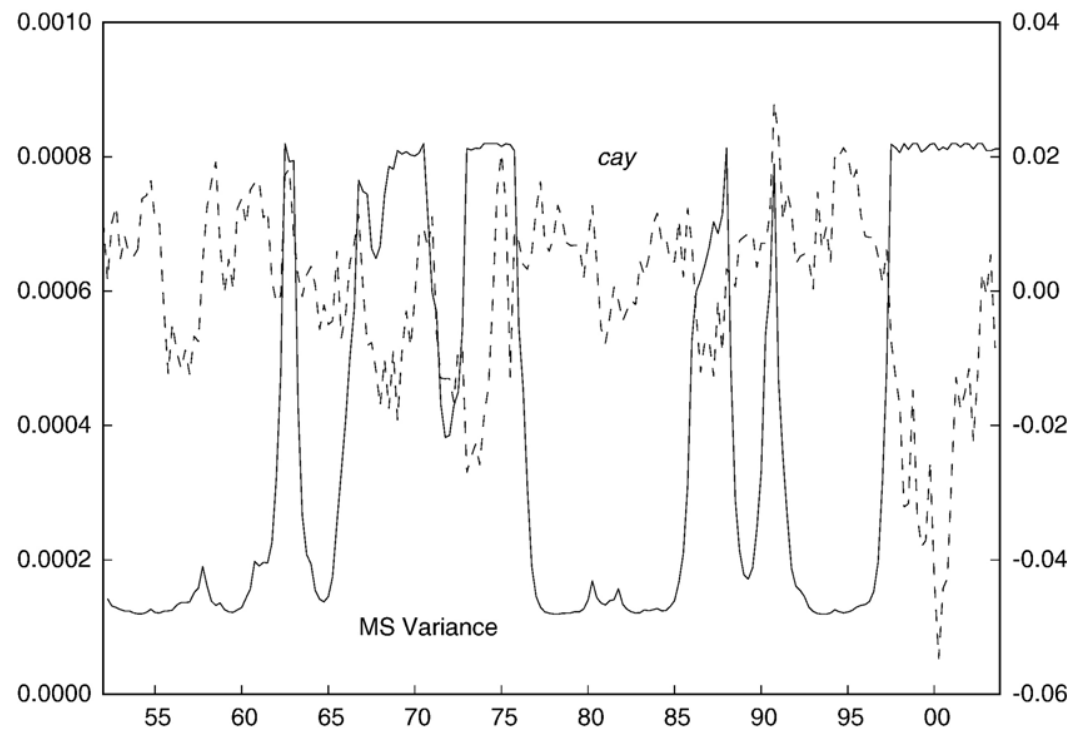

Fig. 5. Markov-switching variance for asset wealth growth vs. cay.

cointegrating vector will have two regimes defined by $S_{t}$, cay $y_{S t}=\left\{\left(\mu_{0}, \beta_{0}, \delta_{0}\right),\left(\mu_{1}, \beta_{1}, \delta_{1}\right)\right\}$, while $\sigma_{V_{t}}=\left\{\sigma_{0}, \sigma_{1}\right\}$ will capture low and high volatility regimes.

Following Phillips (1991), we combine the two separate regime-shift variables $S_{t}$ and $V_{t}$ into a new latent variable $S_{t}^{*}$ indicating the regime operative at time $t$. The new Markov chain is defined as:

$$
\begin{aligned}
& S_{t}^{*}=1 \text { if } S_{t}=1 \text { and } V_{t}=1, \\
& S_{t}^{*}=2 \text { if } S_{t}=0 \text { and } V_{t}=1, \\
& S_{t}^{*}=3 \text { if } S_{t}=1 \text { and } V_{t}=0, \\
& S_{t}^{*}=4 \text { if } S_{t}=0 \text { and } V_{t}=0 .
\end{aligned}
$$

Given that $S_{t}$ and $V_{t}$ are assumed to be independent, the matrix of transition probabilities for $S_{t}^{*}$, with generic element $\operatorname{Pr}\left(S_{t}^{*}=i \mid S_{t-1}^{*}=j\right)$, is given by:

$$
P^{*}=\left[\begin{array}{cccc}
p p^{\prime} & p^{\prime}(1-p) & p\left(1-p^{\prime}\right) & (1-p)\left(1-p^{\prime}\right) \\
p^{\prime}(1-q) & q p^{\prime} & (1-q)\left(1-p^{\prime}\right) & q\left(1-p^{\prime}\right) \\
p\left(1-q^{\prime}\right) & (1-p)\left(1-q^{\prime}\right) & p q^{\prime} & q^{\prime}(1-p) \\
(1-q)\left(1-q^{\prime}\right) & q\left(1-q^{\prime}\right) & q^{\prime}(1-q) & q q^{\prime}
\end{array}\right] .
$$

We will be interested in testing whether this specification can be simplified into one where a single Markov chain induces parameter changes. In this case, the $4 \times 4$ transition matrix will look like:

$$
\left[\begin{array}{cccc}
p & 0 & 0 & (1-p) \\
\cdot & \cdot & \cdot & \cdot \\
\cdot & \cdot & \cdot & \cdot \\
(1-q) & 0 & 0 & q
\end{array}\right]
$$

collapsing into a standard $2 \times 2$ transition matrix. 
Table 3

Markov-switching cointegration estimates

\begin{tabular}{lll}
\hline & Model 1 & Model 2 \\
\hline$\mu_{0}$ & $0.4574(0.026)$ & $0.5961(0.06)$ \\
$\mu_{1}$ & $0.8853(0.049)$ & $0.7749(0.049)$ \\
$\beta_{0}$ & $0.2703(0.010)$ & $0.2944(0.018)$ \\
$\beta_{1}$ & $0.2260(0.014)$ & $0.2177(0.024)$ \\
$\delta_{0}$ & $0.6094(0.010)$ & $0.6051(0.017)$ \\
$\delta_{1}$ & $0.6306(0.012)$ & $0.6761(0.027)$ \\
$\sigma_{0}$ & $0.0034(0.0006)$ & $0.0060(0.0008)$ \\
$\sigma_{1}$ & $0.0108(0.0008)$ & $0.0089(0.0014)$ \\
$p$ & $0.9502(0.048)$ & $0.9270(0.034)$ \\
$q$ & $0.8478(0.046)$ & $0.9429(0.019)$ \\
$p^{\prime}$ & $0.9406(0.032)$ & \\
$q^{\prime}$ & $0.9651(0.047)$ & \\
Log-likelihood & -699.5 & -697.4 \\
AIC & -1375.1 & -1374.7 \\
BIC & -1335.1 & -1341.4 \\
HQ & -1358.9 & -1361.2 \\
LR specification test: & $142.6[0.00]$ & $138.6[0.00]$ \\
LR test for $H_{0}: p=p^{\prime}, q=q^{\prime}: 4.18$ & & \\
\hline
\end{tabular}

Notice that the formulation in Eq. (18) is very flexible, in that it allows the data to determine when and which parameters have shifted, be it the long-run coefficients or the variance - see Hall et al. (1997), for more details on the use of MS models in a cointegration setting. Other papers - for example, Ludvigson and Steindel (1999) and Mehra (2001) - have relied on an adhoc choice of break points. Our model, however, will be able to endogenously distinguish periods where, for instance, asset markets and returns may be behaving differently, and show how this affects the long-run relationship and estimates of the wealth effect. This is particularly convenient for studying the implications of the model developed in the previous section.

Table 3 records the results of maximum likelihood estimation of the parameters of model (18), labelled as Model 1, and respective robust asymptotic standard errors. The next column shows the estimation results when we impose the restriction Eq. (21) on Eq. (18), that is, when we assume that $S_{t}=V_{t}$ for every $t$. For both models, Likelihood Ratio tests of a linear model against the MS specification, ${ }^{4}$ as well as commonly used model selection criteria, ${ }^{5}$ favour the MS model over the linear cointegration specification.

We then ask whether or not changes in the cointegration vector and shifts in the variance are driven by the same latent variable, i.e., to what extent we need two Markov processes to describe the dynamics of the relationship. This is an important point, since we wish to assess the links between shifts in the long-run parameters and swings in volatility. The last line of Table 3 presents an LR test for the hypothesis that $S_{t}=V_{t}$, which would not be rejected at conventional significance levels. However, as the two specifications are non-nested, this statistic must be read with caution, as this is a non-standard testing problem. Alternatively, we can consider model selection criteria such as the Akaike (AIC), Schwarz (BIC) and Hannan-Quinn (HQ). AIC marginally favours

\footnotetext{
${ }^{4}$ The usual asymptotic distribution for the LR statistic is not valid, so we follow Hall et al. (1997, see footnote p.162) in resorting to the test principle suggested by Davies (1987) for inference when nuisance parameters - the transition probabilities in our case - are unidentified under the null.

${ }^{5}$ AIC, BIC and Hannan-Quinn criterion values for the linear model are $-1248.2,-1234.8$ and -1242.7 , respectively.
} 


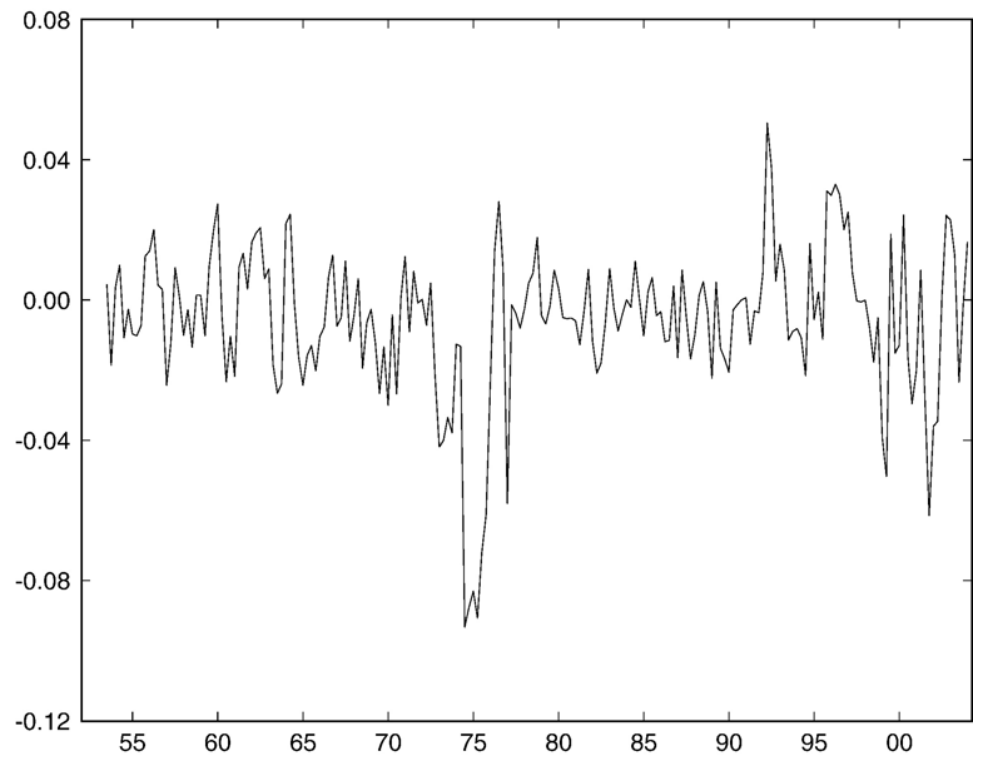

Fig. 6. Standardised residuals from Model 2.

Model 1, while BIC and HQ clearly indicate that Model 2 is a plausible, more parsimonious representation. Also, there are no substantial differences in the numerical values of the estimated parameters in the two models, so we will focus our attention on the results of Model 2.

As suggested by Hall et al. (1997) and Gabriel et al. (2002), the standardised residuals ${ }^{6}$ from estimation of Model 2 can be used for further analysis. These are plotted in Fig. 6. Although they reveal some degree of autocorrelation, negligible in this context, an LM test for neglected ARCH effects with a $p$-value of 0.21 confirms that the swings in volatility have successfully been captured by this model. In addition, an ADF cointegration statistic of -7.043 on the standardised residuals reveals that the estimated MS equilibrium errors are stationary, ${ }^{7}$ rejecting the null of no cointegration at the $1 \%$ significance level (other residual-based tests lead to the same conclusion). Thus, allowing for random shifts between two regimes in the consumption-wealth ratio delivers results consistent with the predicted long-run equilibrium relationship.

Fig. 7 shows the smoothed probabilities for regime 0 produced by Model 2. Inspection of Fig. 7 suggests that this model identifies two distinct cointegrating regimes: regime 1 is associated with more volatile periods, while regime 0 is associated with "calmer" periods. These are very similar to the regimes identified previously, with the univariate analysis of asset returns. Note that the transition probabilities for Model 2 and for the univariate representation of asset wealth growth are virtually the same, indicating relatively persistent regimes.

Furthermore, Table 3 reveals that the long-run coefficients undergo non-negligible changes between regimes. In state 1 , the coefficient associated with asset wealth is smaller (0.22) than in state 0 (0.29), which is consistent with the empirical evidence surveyed in Poterba (2000) and

\footnotetext{
${ }^{6}$ These are computed as $\hat{\varepsilon}_{t}=\frac{c_{t}-\hat{\pi}_{0}\left(\hat{\beta}_{0} a_{t}+\hat{\delta}_{0} y_{t}\right)-\hat{\pi}_{1}\left(\hat{\beta}_{1} a_{t}+\hat{\delta}_{1} y_{t}\right)}{\left(\hat{\pi}_{0} \hat{\sigma}_{0}^{2}+\hat{\pi}_{1} \hat{\sigma}_{1}^{2}\right)^{1 / 2}}$, where $\hat{\pi}_{1}=P\left(S_{t}=i \mid I_{t}\right)$.

${ }^{7}$ Gabriel et al. (2002) show that the usual asymptotic critical values can be used to test for cointegration with standardised residuals.
} 


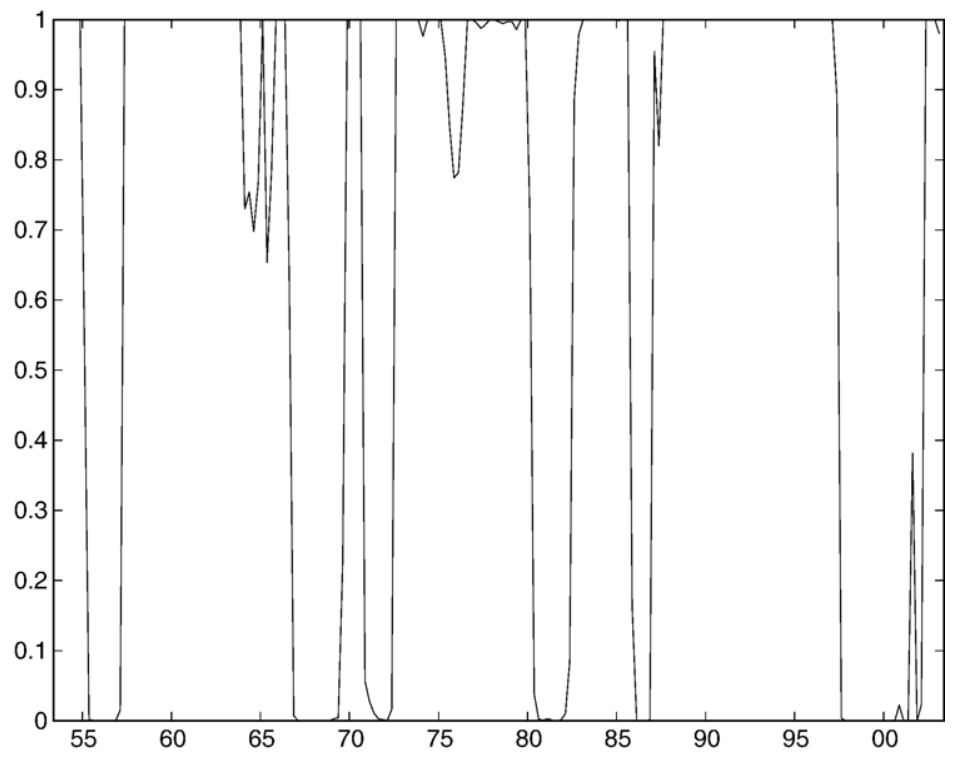

Fig. 7. Regime 0 probabilities.

Mehra (2001), and with our indeterminacy hypothesis. It is interesting to notice that the difference between the $\beta s$ and the $\delta s$ across regimes is approximately the same (0.07). Thus, the cointegration vector estimated by Lettau and Ludvigson (2004) seems to be a "composite" estimate of the different regimes. As shown in Section 2, these matching symmetric variations are also consistent with our derivations - recall Eqs. (11) and (12).

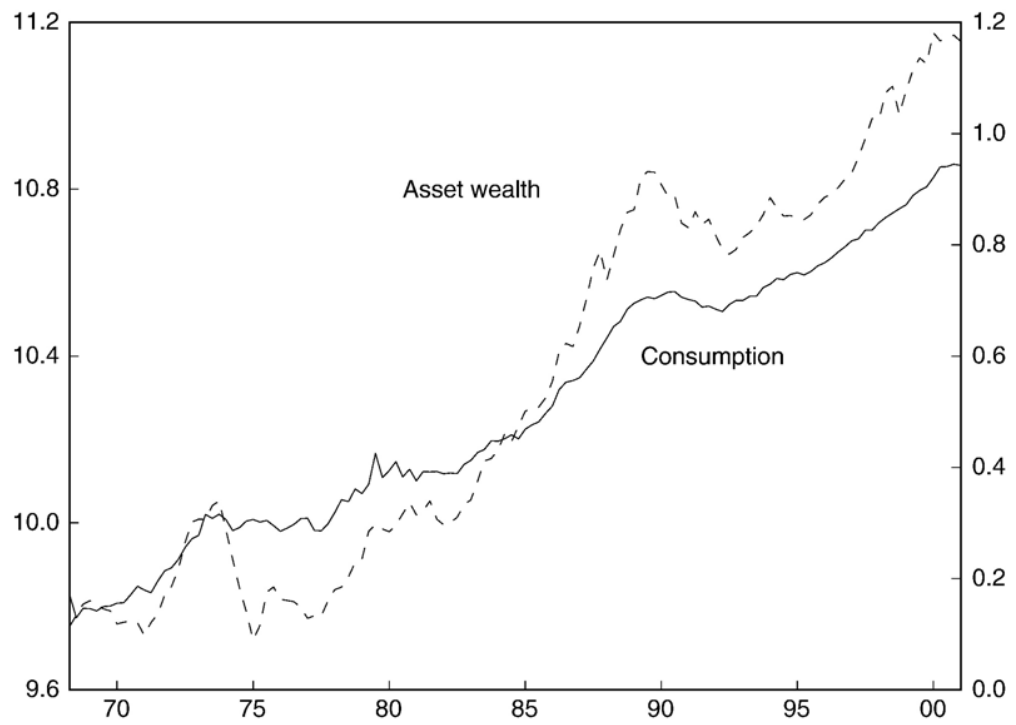

Fig. 8. Levels of consumption and asset wealth, UK. 


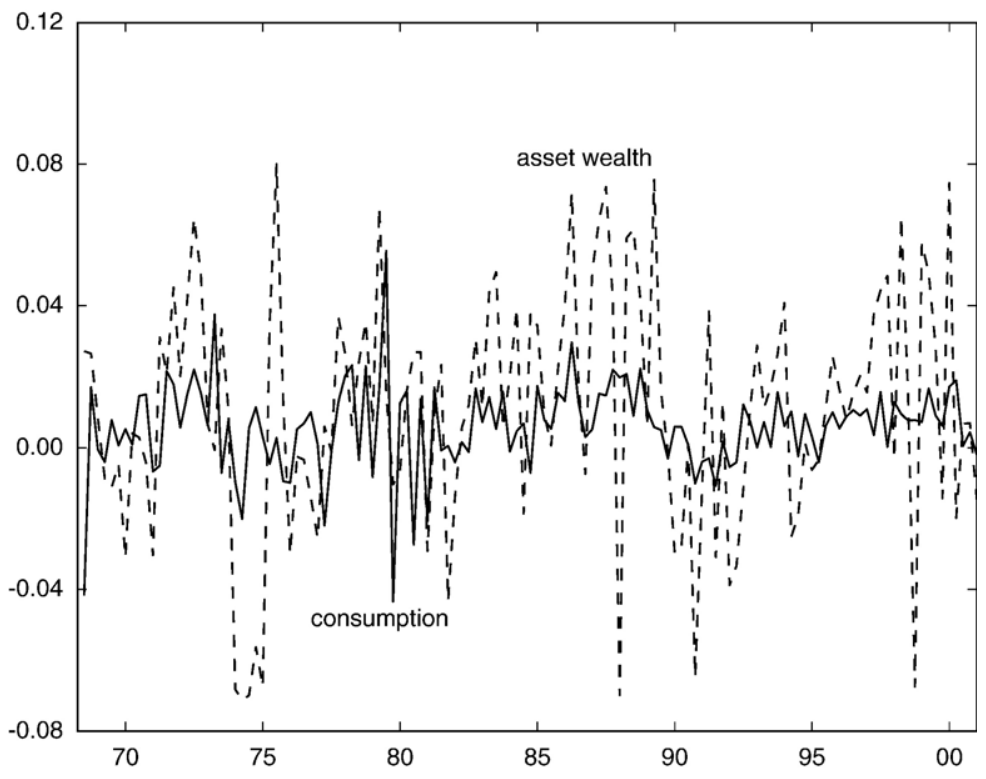

Fig. 9. Consumption and asset wealth growth, UK.

\subsection{Further evidence: the UK case}

Studies dealing with the consumption-wealth relationship using international data do not abound. One possible explanation is the fact that wealth effects are expected to be more prominent in economies where a significant proportion of households' wealth is formed by financial assets, as is the case with the US economy. Slacalek (2004) studies a set of 26 developed countries, finding little evidence of a stable long-run relationship for consumption, labour income and asset wealth, although he does not make use of any of the testing procedures employed in our paper.

We focus on the case of the UK economy ${ }^{8}$ to illustrate how our approach may explain the instability problems encountered in Slacalek (2004). Previous work by Fernandez-Corrugedo et al. (2003) applies the framework of Lettau and Ludvigson (2004) and Lettau and Ludvigson (2004) to UK data, but instability of the cointegrating relationship is overlooked. As we show next, there are strong reasons to suspect that the UK consumption-wealth ratio displays the same type of unstable behaviour as found above for the US.

We use the same dataset as Slacalek (2004) and Fernandez-Corrugedo et al. (2003), comprising quarterly data ${ }^{9}$ on consumption, income and wealth for the period 1968-2000. Figs. 8 and 9 depict the levels and changes in $(\log )$ consumption and wealth (dashed line), which are all similar to the US data, with consumption displaying a much less volatile path than wealth. Univariate analysis of asset returns as in the previous section revealed the time-varying nature of volatility in this series.

The top panel of Table 4 condenses information on cointegration and instability testing. Note that the Johansen tests show very marginal support for the existence of a long-run relationship, while the Gregory-Hansen tests unequivocally reject the null of no cointegration, which gives

\footnotetext{
${ }^{8}$ In order to avoid repetitions, the discussion will be briefer (all unreported results available upon request).

${ }^{9}$ See both papers for details on the definition of variables.
} 
Table 4

Tests and estimation, UK case

\begin{tabular}{lcccccr}
\hline \multicolumn{7}{l}{ Johansen cointegration tests } \\
\cline { 2 - 6 }$H_{0}: r=$ & Trace & $p$-value & $5 \%$ c.v. & Max. & $p$-value & $5 \%$ c.v. \\
\hline 0 & 27.052 & 0.101 & 29.797 & 18.332 & 0.118 & 21.131 \\
1 & 8.719 & 0.392 & 15.494 & 8.714 & 0.311 & 14.264 \\
2 & 0.943 & 3.841 & 0.005 & 0.943 & 3.841 \\
\multicolumn{2}{l}{ Gregory-Hansen } & & & & & $Z_{\alpha}^{*}$ \\
\hline
\end{tabular}

Stability tests

\begin{tabular}{lllll}
\hline Hansen (single-equation) & Mean LM & Sup LM & Exp LM & $\mathrm{L}_{\mathrm{c}}$ \\
\hline$p$-values & 0.026 & $>0.20$ & $4.045^{*}$ & $<0.01$ \\
Seo (system) statistics & $8.766^{* *}$ & 24.887 & 8.436 &
\end{tabular}

Markov-switching estimation

\begin{tabular}{|c|c|c|c|c|c|c|}
\hline$\mu_{0}$ & $\mu_{1}$ & $\beta_{0}$ & $\beta_{1}$ & $\delta_{0}$ & \multicolumn{2}{|l|}{$\delta_{1}$} \\
\hline$-2.629(0.232)$ & $-1.349(0.263)$ & $0.272(0.025)$ & $0.139(0.029)$ & $0.522(0.052)$ & \multicolumn{2}{|c|}{$0.730(0.059)$} \\
\hline$\sigma_{0}$ & $\sigma_{1}$ & $p$ & $q$ & $\mathrm{AIC}$ & $\mathrm{BIC}$ & HQ \\
\hline $0.0097(0.002)$ & $0.0156(0.002)$ & $0.993(0.449)$ & $0.930(0.292)$ & -738.42 & -709.60 & -726.71 \\
\hline \multicolumn{2}{|c|}{ LR specification test: } & $44.522[0.00]$ & & & & \\
\hline
\end{tabular}

**: rejection at the $1 \%$ significance level; *: rejection at the $5 \%$ significance level.

weight to the hypothesis of a long-run relationship subject to regime shifts. ${ }^{10}$ Indeed, the evidence of instability in the cointegration vector is even more stronger than for the US, with the Hansen and Seo stability tests clearly rejecting the null of a stable relationship.

It seems, therefore, sensible to use the Markov-switching approach discussed previously. The bottom half of Table 4 includes the estimation results of Model 2 for the UK. The LR test and the model selection criteria once more favour the switching specification ${ }^{11}$ and the similarities with Table 3 are striking, if not more compelling: the coefficients display sizeable differences between regimes, with the coefficient on wealth halving when switching to regime 1 , the more volatile state. It seems, thus, that the case for an unstable wealth effect is not restricted to a particular dataset, rather being an intrinsic feature of the consumption-wealth relationship which the derivations in Section 2 highlighted.

\section{Conclusion}

This paper documents patterns and sources of instability in the consumption-wealth ratio, offering a model-based explanation that adds to those given in Poterba (2000). We developed our analysis from the point where Lettau and Ludvigson (2001) stopped. These authors estimated the consumption equation and concluded it was consistent with the usual estimates of labour and

\footnotetext{
${ }^{10}$ The estimated cointegrating vector with the Johansen procedure is $(1,-0.13,-0.71)$, similar to the estimates obtained via DOLS, $(1,-0.16,-0.67)$.

${ }^{11}$ AIC, BIC and Hannan-Quinn criterion values for the linear model are $-705.90,-694.37$ and -701.22 , respectively.
} 
capital income shares. We have shown that if we accept this conclusion, then the consumption function is likely to show signs of instability, and in the simple case studied here it would even lead to indeterminacy. If we accept the assumptions employed in the standard derivation of the wealth effect - that consumption tends to a stationary fraction of wealth, that the average weight of human wealth on total wealth is stationary and that labour income captures the non-stationarity in human wealth - then the algebra of I(1) variables says we should also conclude that there is cointegration between any two-element combination of consumption, wealth and labour income, an implication already noted by Galí (1990). This is in fact another instance of indeterminacy, but one that apparently is not upheld by the data. On the other hand, the implication of the model we have just presented that the estimated "wealth effect" should be unstable, does in fact appear to be matched by the data, as reported in Section 3. Indeed, we estimated a simple Markov-switching model and found different estimates of the "wealth effect" associated with two regimes. These regimes seem to correspond to periods of high/low volatility in asset prices, corroborating, in a Popperian way, the predictions of our derivations.

\section{Acknowledgements}

The authors are grateful to Piergiorgio Alessandri, John Driffill, Zacharias Psaradakis, Ron Smith, Martin Sola and participants in the workshop "Monetary Policy and Asset Prices", held at the University of Minho, in the 12th Conference of the Society of Computational Economics, held in Cyprus, and in seminars at University of Coimbra and Technical University of Lisbon for their helpful comments. The usual disclaimer applies. The authors also acknowledge financial support provided by the Portuguese Foundation for Science and Technology under research grant POCI/ EGE/56054/2004 (partially funded by FEDER).

\section{Appendix A. Supplementary data}

Supplementary data associated with this article can be found, in the online version, at doi:10.1016/j.econmod.2007.04.004.

\section{References}

Campbell, J.Y., Mankiw, N.G., 1989. Consumption, income and interest rates: reinterpreting the time series evidence. In: Blanchard, O.J., Fischer, S. (Eds.), NBER Macroeconomics Annual. The MIT Press, Cambridge, MA, pp. $185-216$. Cecchetti, S.G., Lam, P.-S., Mark, N.C., 1990. Mean reversion in equilibrium asset prices. American Economic Review 80 (3), $398-418$.

Davies, R.B., 1987. Hypothesis testing when a nuisance parameter is present only under the alternative. Biometrika 74 (1), $33-43$.

Driffill, J., Sola, M., 1998. Intrinsic bubbles and regime-switching. Journal of Monetary Economics 42 (2), $357-373$.

Fernandez-Corrugedo, E., Price, S., Blake, A., 2003. The dynamics of consumers' expenditure: the UK consumption ECM redux. Working Paper, vol. 204. Bank of England.

Gabriel, V.J., Psaradakis, Z., Sola, M., 2002. A simple method of testing for cointegration subject to multiple regime changes. Economics Letters 76 (2), 213-221.

Galí, J., 1990. Finite horizons, life-cycle savings, and time-series evidence on consumption. Journal of Monetary Economics 26 (3), 433-452.

Gregory, A.W., Hansen, B.E., 1996. Residual-based tests for cointegration in models with regime shifts. Journal of Econometrics 70 (1), 99-126.

Guidolin, M., Timmerman, A., 2005. Strategic asset allocation and consumption decisions under multivariate regime switching. Working Papers, vol. 2005-002. Federal Reserve Bank of St. Louis. available at http://ideas.repec.org/p/fip/ fedlwp/2005-002.html. 
Hall, S.G., Psaradakis, Z., Sola, M., 1997. Cointegration and changes in regime: the Japanese consumption function. Journal of Applied Econometrics 12 (2), 151-168.

Hansen, B.E., 1992. Tests for parameter instability in regressions with I(1) processes. Journal of Business and Economic Statistics 10 (3), 321-335.

Hornstein, A., Krusell, P., Violante, G.L., 2005. The effects of technical change on labor market inequalities. In: Aghion, P., Durlauf, S. (Eds.), Handbook of Economic Growth. Elsevier, pp. 1275-1370.

Lettau, M., Ludvigson, S., 2001. Consumption, aggregate wealth, and expected stock returns. Journal of Finance 56 (3), 815-849.

Lettau, M., Ludvigson, S., 2004. Understanding trend and cycle in asset values: reevaluating the wealth effect on consumption. American Economic Review 94 (1), 276-299.

Ljungqvist, L., Sargent, T., 2004. Recursive Macroeconomic Theory. The MIT Press, Cambridge, MA.

Ludvigson, S., Steindel, C., 1999. How important is the stock market effect on consumption? Federal Reserve Bank of New York Economic Policy Review, 5 (2), pp. 29-51.

McConnell, M.M., Perez-Quiros, G., 2000. Output fluctuations in the United States: what has changed since the early 1980'? American Economic Review 90 (5), 1464-1476.

Mehra, Y.P., 2001. The wealth effect in empirical life-cycle aggregate consumption equations. Federal Reserve Bank of Richmond Economic Quarterly, 87 (2), pp. 45-68.

Phillips, K.L., 1991. A two-country model of stochastic output with changes in regime. Journal of International Economics $31(1-2), 121-142$.

Poterba, J.M., 2000. Stock market wealth and consumption. Journal of Economic Perspectives 14 (2), $99-118$.

Seo, B., 1998. Tests for structural change in cointegrated systems. Econometric Theory 14 (2), 222-259.

Slacalek, J., 2004. International evidence on cointegration between consumption, income and wealth. Unpublished manuscript. Available at http://www.slacalek.com/research.html.

Rudd, J., Whelan, K., 2006. Empirical proxies for the consumption-wealth ratio. Review of Economic Dynamics 9 (1), $34-51$. 